\title{
Acute pulmonary embolus with visible right heart thrombus in transit
}

\author{
Michael Thomas Debney \\ Cardiology Department, Imperial College NHS Healthcare Trust, London, UK
}

Correspondence to Dr Michael Thomas Debney, mikedebney@googlemail.com

\section{DESCRIPTION}

A 29-year-old woman presented to our emergency department with syncope, acute chest pain and circulatory collapse. She had a tachycardia of $135 \mathrm{bpm}$, blood pressure of $77 / 55 \mathrm{~mm} \mathrm{Hg}$ and a profound metabolic acidosis ( $\mathrm{pH}$ 7.07, lactate 10, base excess-20). A 12-lead ECG (figure 1) showed sinus tachycardia with right axis deviation, large $\mathrm{p}$ waves and poor $\mathrm{R}$ wave progression across the chest leads, suggestive of acute right heart strain. A D-dimer was elevated at $15984 \mu \mathrm{g} / \mathrm{l}$ (reference range 0-200 $\mu \mathrm{g} / \mathrm{l}$ ); a plain anteroposterior chest radiograph was unremarkable. Bedside transthoracic echocardiography showed a dilated, poorly functioning right ventricle with visible thrombus prolapsing across the tricuspid valve as demonstrated in figure 2 and video 1 . These findings confirmed the clinical suspicion of acute massive pulmonary embolus causing circulatory collapse and intravenous thrombolysis was successfully administered. Once haemodynamic stability had been restored, CT pulmonary angiography confirmed massive bilateral pulmonary emboli. Acute pulmonary embolus with visible right-heart thrombi is a rare phenomenon ${ }^{1}$ associated with a poor prognosis. ${ }^{2}$ Bedside transthoracic echocardiography is important in the visualisation of the right ventricle in the setting of circulatory collapse and can be used to identify thrombus in-transit. ${ }^{3}$ European Society of Cardiology guidelines ${ }^{4}$ state that unstable patients with high-risk pulmonary embolism (shock, hypotension) and echocardiography signs of right ventricle overload should be considered for thrombolysis as an emergency, life-saving treatment, as demonstrated in our case. The patient made an uneventful recovery and was discharged home on oral anticoagulant 8 days later. No obvious cause or specific risk factors for pulmonary embolus have yet been identified, although a full haematological assessment is pending.

Video 1 Apical four chamber view showing visible clot prolapsing across the tricuspid valve from right atrium into right ventricle.

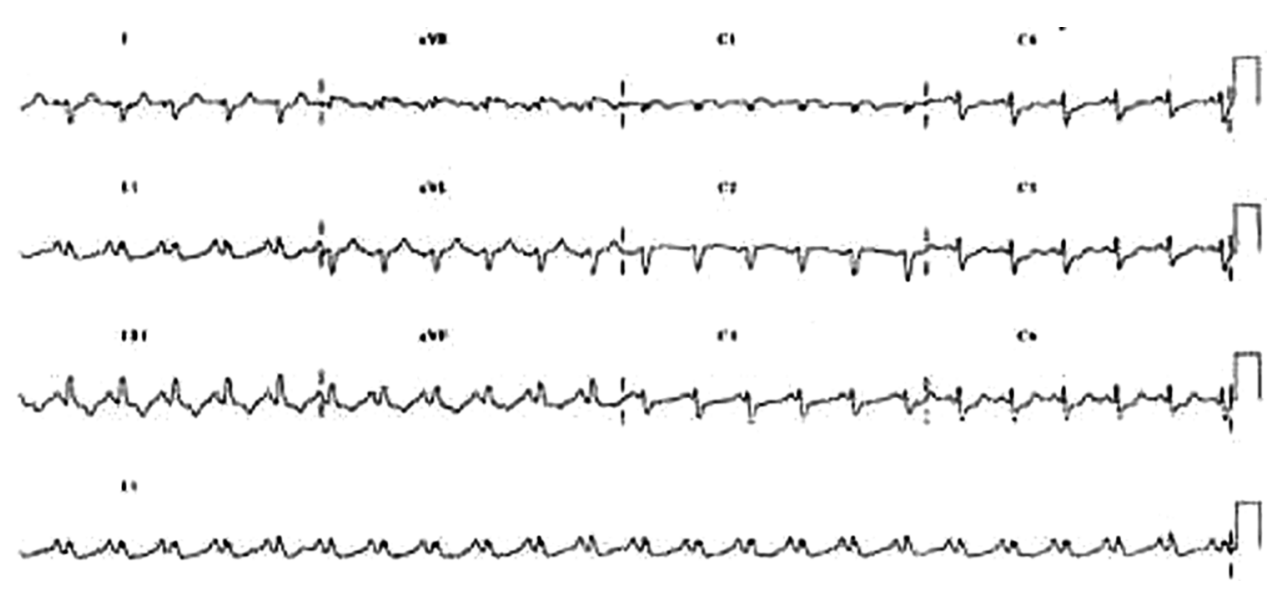

Figure 1 12-lead ECG showing sinus tachycardia, right axis deviation, large $\mathrm{p}$ waves and poor $\mathrm{r}$ wave progression across the chest leads, consistent with right heart strain. 


\section{BMJ Case Reports}

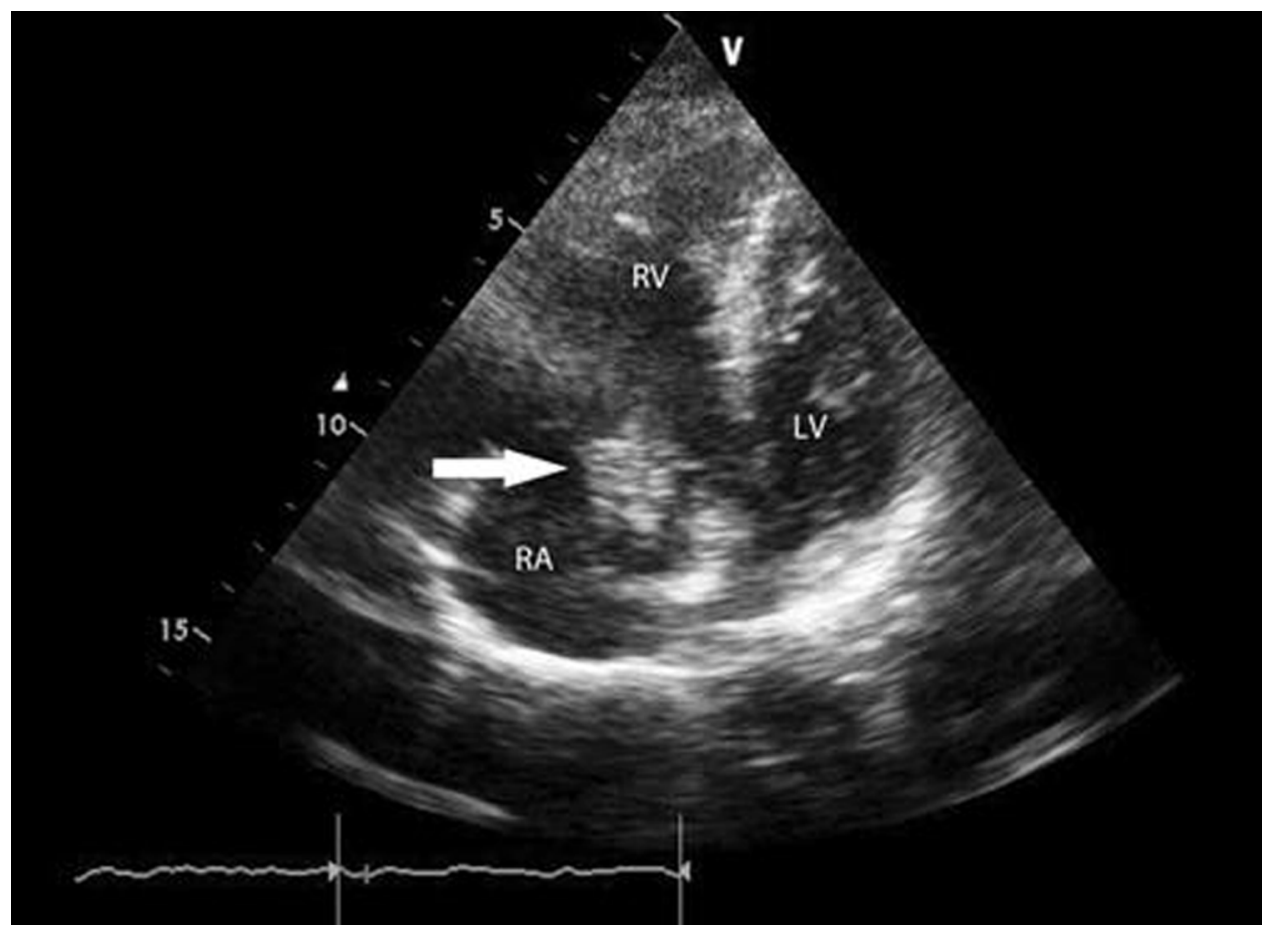

Figure 2 Apical four chamber view with visible clot (arrow) prolapsing across the tricuspid valve from right atrium into right ventricle. RA - Right Atrium, RV - Right Ventricle, LV - Left Ventricle.

\section{Competing interests None.}

Patient consent Obtained.

\section{REFERENCES}

1. Chapoutot L, Nazeyrollas P, Metz D, et al. Floating right heart thrombi and pulmonary embolism: diagnosis, outcome and therapeutic management. Cardiology 1996;87:169-74.
2. European working group on echocardiography. The European cooperative study on the clinical significance of right heart thrombi. Eur Heart $J$ 1989;10:1046-59.

3. Chartier L, Béra J, Delomez $\mathrm{M}$, et al. Free-floating thrombi in the right heart: diagnosis, management, and prognostic indexes in 38 consecutive patients. Circulation 1999;99:2779-83.

4. Guidelines on the diagnosis and management of acute pulmonary embolism. The task force for the diagnosis and management of acute pulmonary embolism of the European Society of Cardiology (ESC). Eur Heart J 2008;29:2276-315.

This pdf has been created automatically from the final edited text and images.

Copyright 2011 BMJ Publishing Group. All rights reserved. For permission to reuse any of this content visit http://group.bmi.com/group/rights-licensing/permissions.

BMJ Case Report Fellows may re-use this article for personal use and teaching without any further permission.

Please cite this article as follows (you will need to access the article online to obtain the date of publication)

Debney MT. Acute pulmonary embolus with visible right heart thrombus in transit. BMJ Case Reports 2011;10.1136/bcr.07.2011.4553, date of publication

Become a Fellow of BMJ Case Reports today and you can:

- Submit as many cases as you like

- Enjoy fast sympathetic peer review and rapid publication of accepted articles

- Access all the published articles

Re-use any of the published material for personal use and teaching without further permission

For information on Institutional Fellowships contact consortiasales@bmjgroup.com

Visit casereports.bmj.com for more articles like this and to become a Fellow 